\title{
Film Cooling from a Single Row of Compound Angle Holes at High Blowing Ratios
}

\author{
PHILLIP M. LIGRANI \\ Convective Heat Transfer Laboratory, Department of Mechanical Engineering, University of Utah, Salt Lake City, Utah 84112 \\ JOON SIK LEE \\ Turbo and Power Machinery Research Center, Department of Mechanical Engineering, Seoul National University, Seoul 151-742, \\ Korea
}

\begin{abstract}
Experimental results are presented which describe the development and structure of flow downstream of a single row of holes with compound angle orientations producing film cooling at high blowing ratios. This film cooling configuration is important because similar arrangements are frequently employed on the first stage of rotating blades of operating gas turbine engines. With this configuration, holes are spaced $6 \mathrm{~d}$ apart in the spanwise direction, with inclination angles of 24 degrees, and angles of orientation of 50.5 degrees. Blowing ratios range from 1.5 to 4.0 and the ratio of injectant to freestream density is near 1.0. Results show that spanwise averaged adiabatic effectiveness, spanwise-averaged iso-energetic Stanton number ratios, surveys of streamwise mean velocity, and surveys of injectant distributions change by important amounts as the blowing ratio increases. This is due to injectant lift-off from the test surface just downstream of the holes.
\end{abstract}

Key Words: Gas Turbines; Film Cooling; Compound Angle Holes; Turbine Blades; Film Effectiveness

\section{INTRODUCTION}

$\mathbf{I}^{\mathrm{n}}$ nvestigations of film cooling from holes with compound angle orientations are described by Mayle and Camarata (1975), Kim et al. (1978), Ligrani et al. (1992, 1994a, 1994b), Sen et al. (1994), Schmidt et al. (1994), and Ekkad et al. (1995a, 1995b). Investigations of lateral film cooling injection from holes in spanwise/normal planes are described by Goldstein et al. (1970), Honami and Fukagawa (1987), Sathyamurthy and Patankar (1990), Honami et al. (1994), and Ligrani et al. (1996a, 1996b).

Of the studies of film cooling from compound angle holes, Mayle and Camarata (1975) studied the effects of hole spacing and blowing ratio on heat transfer and film effectiveness for a staggered-hole array. The holes were angled 30 degrees to the plate surface in planes oriented 45 degrees from the flow direction. Spanwise spacings between holes were $8 \mathrm{~d}, 10 \mathrm{~d}$ and $14 \mathrm{~d}$. Higher values of effectiveness were measured downstream of the holes with the smaller spacings. Kim, Moffat and Kays (1978) investigated heat transfer to a full coverage, film-cooled surface with holes having the same angles as employed by Mayle and Camarata (1975). For one injection temperature and one blowing ratio, Kim et al. (1978) concluded that heat transfer coefficients downstream of the compound angle configuration were half as high as ones measured downstream of simple angle holes slanted 30 degrees from the test surface.

Ligrani et al. (1994b), Sen et al. (1994), and Schmidt et al. (1994) present results for the same 6d spanwise hole spacing employed here. Of these investigations, Ligrani et al. (1992, 1994a, 1994b) present results from a systematic investigation conducted to compare results from compound angle and simple angle film hole arrangements. From a comparison of spanwise averaged adiabatic effectiveness values, the compound angle injection configuration provides significantly improved protection compared to the simple angle configuration for the same spanwise hole spacing, normalized streamwise location, and blowing ratio within 60 diameters of the injection holes. Sen et al. (1994), and Schmidt et al. 
(1994) compare adiabatic effectiveness and iso-energetic heat transfer coefficient ratio from three different hole arrangements, one simple angle, one compound angle, and one compound angle with diffusing expanded exit.

The present paper gives results from compound angle film holes at blowing ratios from 1.5 to 4.0 , which are generally higher than the ones presented in earlier studies. Such compound angle film cooling holes are different from simple angle holes because the coolant is ejected with a spanwise velocity component relative to the mainstream flow. Film holes with compound angle orientations are often used in place of simple angle holes because they are believed to produce injectant distributions over surfaces which give better higher film effectiveness values and lower overall heat transfer rates. The spanwise spacing of the holes employed here is $6 \mathrm{~d}$, an arrangement often used on endwall and blade surfaces of turbines, making them important to designers of these components. $6 \mathrm{~d}$ spanwise hole spacing is also helpful because it allows understanding of film cooling phenomena which are not apparent from configurations with more closely spaced holes. This is because the relatively large hole spacing results in minimal coalescence and interactions between injectant fluid from adjacent holes, particularly at small $\mathrm{x} / \mathrm{d}$.

\section{EXPERIMENTAL APPARATUS AND PROCEDURES}

Details on the experimental apparatus and procedures are presented by Ligrani et al. (1992, 1994a, 1994b) and by
Ligrani and Ramsey (1996a, 1996b). A brief summary is also included here.

\section{Wind Tunnel, Coordinate System and Injection System}

The wind tunnel facility is open-circuit and subsonic. A centrifugal blower is located at the upstream end, followed by a diffuser, a header containing a honeycomb and three screens, and then a 16 to 1 contraction ratio nozzle. The nozzle leads to the test section which is a rectangular duct $3.05 \mathrm{~m}$ long, $0.61 \mathrm{~m}$ wide, and $0.203 \mathrm{~m}$ high at its entrance with a top wall having adjustable height. The freestream velocity is $10 \mathrm{~m} / \mathrm{s}$ and the freestream turbulence intensity is quite low at approximately 0.13 percent ( $13 / 100$ of one percent) based on the same velocity. The boundary layer is tripped using a 2 mm high spanwise uniform strip of tape near the nozzle exit $1.072 \mathrm{~m}$ upstream of the constant heat flux transfer surface. A schematic of the test surface is shown in Figure 1. In regard to the coordinate system, $\mathrm{z}$ is the spanwise coordinate measured from the test section spanwise centerline, $\mathrm{X}$ is measured from the upstream edge of the boundary layer trip, and $\mathrm{y}$ is measured normal to the test surface. $\mathrm{x}$ is measured from the downstream edge of the injection holes and generally presented as $\mathrm{x} / \mathrm{d}$. The total boundary layer thickness just downstream of the injection holes ( $\mathrm{x} / \mathrm{d}=2.75$ with no film cooling) is $0.973 \mathrm{~cm}$ giving a thickness to hole diameter ratio of 1.03 . The ratios of momentum thickness to hole diameter and displacement thickness to hole diameter at this location are then 0.13 and 0.22 , respectively.

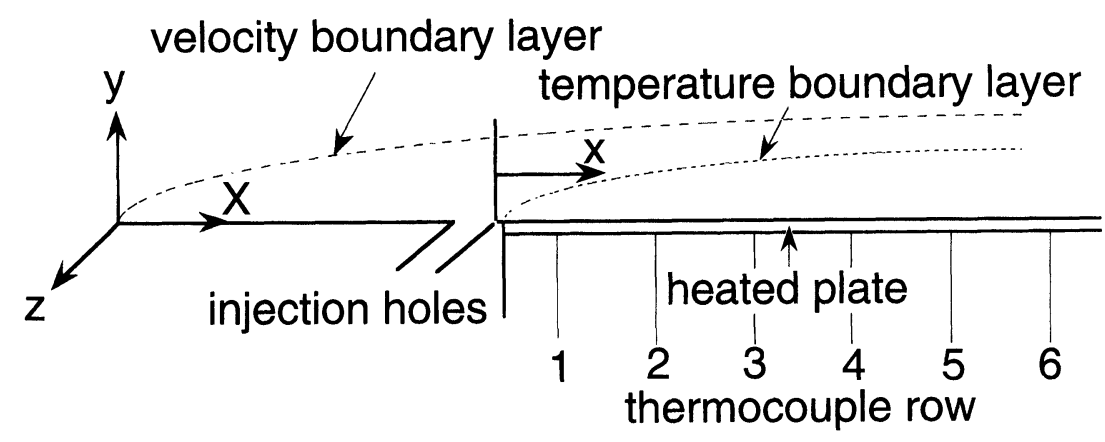

\footnotetext{
Distance between trip and downstream edges of holes $=1.060 \mathrm{~m}$

Injection hole angle with respect to the test surface as projected into the streamwise/normal plane, $\Omega=35^{\circ}$

Injection hole angle with respect to the test surface as projected into the spanwise/normal plane, $\beta=30^{\circ}$
}

FIGURE 1 Schematic of test section and coordinate system. 
The injection system is described by Ligrani, et al. (1992, 1994a, 1994b). With this system and test plate heating, the non-dimensional injection temperature parameter $\theta$ is maintained at values ranging from 0.0 to 3.0 , which includes values within the range of gas turbine component operation. The ratio of injectant to freestream density $\rho_{\mathrm{c}} / \rho_{x}$ is from 0.94 to 1.00 . The upper surface of the plenum chamber is connected to the injection tubes of the different injection configurations, where each tube is about $7.6 \mathrm{~cm}$ long, giving a length to diameter ratio of about 8 .

\section{Stanton Number Measurements}

The heat transfer surface is also described by Ligrani et al. (1992, 1994a, 1994b). It is designed to provide a constant heat flux over its area using a surface next to the air stream which is stainless steel foil painted flat black. Immediately beneath this is a linear containing 126 thermocouples, which is just above an Electrofilm Corp. etched foil heater rated at 120 volts and 1500 watts. Located below the heater are several layers of insulating materials including Lexan sheets, foam insulation, Styrofoam and balsa wood. To determine the heat loss by conduction, an energy balance is performed. Radiation losses from the top of the test surface are analytically estimated. The thermal contact resistance between thermocouples and the foil top surface is based on a correlation dependent on heat flux through the foil, thermocouple readings and measurements from calibrated liquid crystals on the surface of the foil. Corrections to account for streamwise and spanwise conduction along the test surface are also employed using procedures developed and described by Wigle (1991).

Copper-constantan thermocouples are used to measure temperatures along the surface of the test plate and the freestream temperature. Voltages from thermocouples are digitally sampled and read using Hewlett-Packard $44422 \mathrm{~T}$ thermocouple relay multiplexer cards, and a Hewlett-Packard 3497A Data Acquisition Control Unit with a 3498A Extender. These units are controlled by a Hewlett-Packard Series 9000 Model 310 computer.

\section{Adiabatic Film Cooling Effectiveness Measurements}

Adiabatic film cooling effectiveness values are determined using linear superposition theory applied to Stanton number ratios measured at different injection temperatures. To do this, local adiabatic film effectiveness values are determined from measurements of local $\mathrm{St} / \mathrm{St}_{\mathrm{o}}$ at different magnitudes of the non-dimensional injection temperature, $\theta$. In equation form,

$$
\mathrm{St} / \mathrm{St}_{\mathrm{o}}=\mathrm{St}_{\mathrm{f}} / \mathrm{St}_{\mathrm{o}}(1-\eta \theta)
$$

where the heat transfer coefficients in $\mathrm{St}$ and $\mathrm{St}_{\mathrm{o}}$ are based on the $\left(\mathrm{T}_{\mathrm{w}}-\mathrm{T}_{\mathrm{r}},{ }_{\infty}\right)$ temperature difference, and the heat transfer coefficient in $\mathrm{St}_{\mathrm{f}}$ is based on the $\left(\mathrm{T}_{\mathrm{w}}-\mathrm{T}_{\mathrm{aw}}\right)$ temperature difference. To determine $\mathrm{St}_{\mathrm{f}} / \mathrm{St}_{\mathrm{o}}$ locally, $\mathrm{St} / \mathrm{St}_{\mathrm{o}}$ is measured at $\theta=0$. To determine $\eta$ locally, $\mathrm{St} / \mathrm{St}_{\mathrm{o}}$ versus $\theta$ data are extrapolated to $\mathrm{St} / \mathrm{St}_{\mathrm{o}}=0$, where $\eta=1 / \theta$. Additional details of this approach are described by Ligrani et al. (1992, 1994a, 1994b), including a test to check the procedure using a direct $\eta$ measurement with a near adiabatic condition on the test plate. $\eta$ differences from the two techniques were always less than experimental uncertainties, which range from 0.01 to 0.03 effectiveness units (Ligrani and Ramsey, 1996a, 1996b).

This approach applies only so long as temperature variations are small enough that fluid properties are reasonably invariant as $\theta$ is changed, and as long as fluid properties are reasonably invariant with respect to all three coordinate directions (Ligrani et al., 1992). In addition, the three-dimensional energy equation which describes the flow field must be linear and homogeneous in its dependent variable, temperature. To meet these conditions, near constant property conditions are maintained throughout the boundary layer by employing low subsonic speeds and temperature differences which are generally less than $30^{\circ} \mathrm{C}$.

\section{Baseline Data Checks}

Baseline data checks were made with no film cooling. Repeated measurements of spanwise-averaged Stanton numbers show good agreement (maximum deviation is 4 percent) with the correlation for turbulent heat transfer to a flat plate with unheated starting length and constant heat flux boundary condition. Ligrani et al. (1992, 1994a, 1994b) provide additional details.

\section{INJECTION CONFIGURATION}

The present injection configuration is designated by Ligrani et al. (1992, 1994a, 1994b) as configuration 3. A schematic drawing showing the film hole geometry is presented in Figure 2. Here, the hole arrangement along the test surface ( $x-z$ plane) is shown as seen in the negative y direction. Holes are placed in a single row with $6 \mathrm{~d}$ spanwise spacing between adjacent holes. The row contains five injection cooling holes arranged so that the centerline of the middle hole is located on the spanwise centerline $(\mathrm{z}=0.0 \mathrm{~cm})$ of the test surface. Hole diameter $\mathrm{d}$ is $0.925 \mathrm{~cm}$. Compound angle holes are 


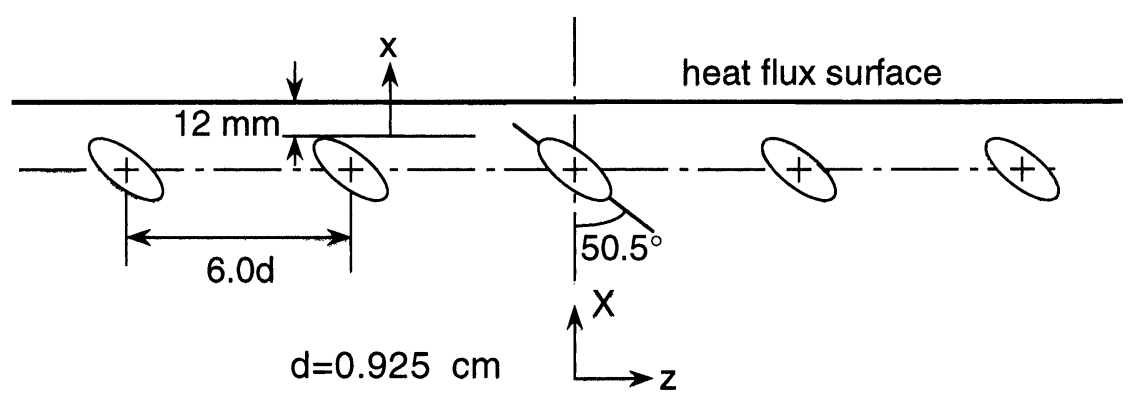

FIGURE 2 Test surface injection geometry for configuration 3 compound angle film cooling holes.

employed with $\Omega=35$ degrees and $\beta=30$ degrees, where $\Omega$ is the angle of the injection holes with respect to the test surface as projected into the streamwise/ normal plane, and $\beta$ is the angle of the injection holes with respect to the test surface as projected into the spanwise/normal plane. Thus, holes are oriented so that the spanwise components of injectant velocity are directed in the negative $\mathrm{z}$ direction. The hole inclination angle is then 24 degrees, and the angle of orientation is 50.5 degrees. This means that the plane of each injection hole is angled at 50.5 degrees from the streamwise/ normal ( $\mathrm{x}-\mathrm{y})$ plane, and, within the plane of each hole, hole centerlines are oriented at angles of 24 degrees from the plane of the test surface $(x-z)$.

\section{EXPERIMENTAL RESULTS}

Measurements downstream of the compound angle film cooling holes are discussed in this section. These include distributions of adiabatic film cooling effectiveness, distributions of iso-energetic Stanton number ratios, surveys of streamwise mean velocity, surveys of injectant distributions, and distributions of the film cooling performance parameter.

\section{Spanwise-Averaged Adiabatic Film Cooling Effectiveness}

Spanwise-averaged magnitudes of effectiveness and Stanton number are determined from local measurements of these quantities for each thermocouple row by averaging the first 13 data points from each row over a $\mathrm{z} / \mathrm{d}$ range from -13.7 to 2.7 . This range of $z / d$ is employed because it corresponds to the spanwise distance between the centerlines of the first and fourth injection holes (accounting for the spanwise spacings between adjacently placed thermocouples), and thus also to three complete variations of injectant concentrations across the span of the test surface. These same spanwise locations are also used because the spanwise trajectory of the film causes the film to move in the negative $\mathrm{z}$ direction after it exits the injection holes. This results in regions with little film coverage on the downstream portions of the test surface at $z / d>2.7$.

Spanwise-averaged values of the adiabatic film cooling effectiveness measured downstream of the single row of configuration 3 compound angle holes are presented in figure 3. Results are given for blowing ratios of 1.5, 2.0, 3.0 and 4.0 at $\mathrm{x} / \mathrm{d}$ of $6.8,17.6,33.8,55.5,77.1$, and 98.7. Results for $\mathrm{m}=0.5$ and $\mathrm{m}=1.0$ from Ligrani et al. (1994b) are included in figure 3 for comparison.

Figure 3 shows that $\bar{\eta}$ generally decreases with $\mathrm{x} / \mathrm{d}$ for each blowing ratio as injectant is diffused and advected downstream. The highest spanwise-averaged effectiveness magnitudes at $\mathrm{x} / \mathrm{d}<40$ are measured at $\mathrm{m}=0.5$ and $m=1.0$. The next highest spanwise-averaged effectivenes

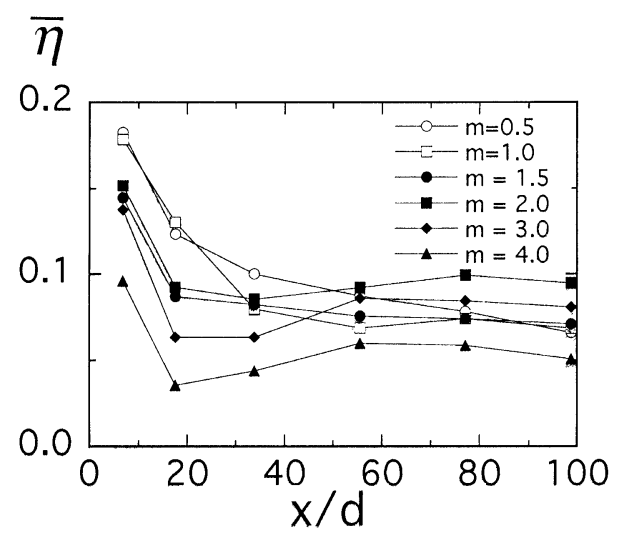

FIGURE 3 Spanwise-averaged magnitudes of adiabatic film cooling effectiveness as dependent upon normalized streamwise distance downstream of one row of compound angle configuration 3 film cooling holes. 
magnitudes are measured at $\mathrm{m}=1.5$ and $\mathrm{m}=2.0$. Because the $\bar{\eta}$ distributions for these two $m$ are nearly the same, the lift-off characteristics are probably somewhat similar. As $\mathrm{m}$ increases further, effectiveness values decrease at these locations $(x / d<40)$ as the injectant lifts off of the test surface by increasing amounts. Lift-off becomes more severe as injectant momentum increases, and results in accumulation of freestream and boundary layer fluid between the film and the surface. This diminishes the insulating characteristics of the film as well as the accompanying thermal protection ordinarily provided by it at lower $m$.

With the exception of the $\mathrm{m}=1.5$ data, spanwiseaveraged effectiveness values at $\mathrm{x} / \mathrm{d}>40$ also decrease at each $\mathrm{x} / \mathrm{d}$ at the blowing ratio increases. According to results described by Wigle (1991), the different trend observed for $m=1.5$ is due to differences in the ways in which the injectant at different blowing ratios lift-offs and spreads relative to the test surface. It is interesting to note that the lowest effectiveness magnitudes in Figure 3 at all $\mathrm{x} / \mathrm{d}$ are obtained with $\mathrm{m}=4.0$.

As mentioned, the ratio of injectant to freestream density, $\rho_{c} / \rho_{x}$, in the present study varies from 0.94 to 1.00. In the first turbine stages of operating gas turbines, the ratio ranges from 1.5 to 2.0 . In some cases, the interaction of the injectant with the boundary layer and mainstream flow, and the resulting spanwise-averaged effectiveness and overall film cooling performance, are strongly affected by changing $\rho_{\mathrm{c}} / \rho_{\mathfrak{x}}$, whereas effects at other experimental conditions can be quite minimal. According to Pedersen et al. (1977), the spanwiseaveraged effectiveness $\bar{\eta}$ downstream of a single row of simple-angle film cooling holes (angled at $35^{\circ}$ from the test surface and spanwise spaced $3 \mathrm{~d}$ apart) for $\mathrm{m}=1.96$ show relatively small changes to $\bar{\eta}$ as $\rho_{c} / \rho_{\varkappa}$ changes from 0.963 to 2.00 . As this occurs, $\bar{\eta}$ decreases only from $.10-.14$ to $.08-.12$ at respective $\mathrm{x} / \mathrm{d}$ ranging from 20 to 90. Pedersen et al. (1977) further indicate that the consequences of varying $\rho_{c} / \rho_{\varkappa}$ are much more significant at $\mathrm{m}=1.05$ and $\mathrm{m}=0.515$, but then diminish entirely at $\mathrm{m}=0.213$. Such trends suggest somewhat less $\bar{\eta}$ dependence on $\rho_{c} / \rho_{x}$ at higher blowing ratios above 1.9 and at lower blowing ratios below 0.3 . At $\mathrm{m}=0.515$ and $\mathrm{m}=1.05$, the changes to spanwise-averaged effectiveness described by Pedersen et al. from changing $\rho_{\mathrm{c}} / \rho_{x}$ occur because, as $\rho_{c} / \rho_{x}$ decreases to approach 1 , films are more likely to lift-off prematurely, penetrate farther away from the surface into the bulk flow, and reattach at larger distances sometimes with higher turbulent mixing. Such changes are due to increased momentum flux ratios at lower $\rho_{\mathrm{c}} / \rho_{x}$ provided blowing ratio $\mathrm{m}$ is held constant as the comparisons are made.

\section{Spanwise-Averaged Iso-Energetic Stanton Number Ratios}

Spanwise-averaged iso-energetic Stanton number ratios are given in Figure 4 for $\mathrm{m}$ of 1.5, 2.0, 3.0, and 4.0. Results for $\mathrm{m}=0.5$ and $\mathrm{m}=1.0$ from Ligrani et al. (1994b) are included for comparison. Several interesting trends are apparent for each blowing ratio greater than or equal to 1.5. First, $\overline{\mathrm{St}_{\mathrm{f}} / \mathrm{St}_{\mathrm{o}}}$ values for all blowing ratios for all $\mathrm{x} / \mathrm{d}$ are greater than 1.0. Second, little $\overline{\mathrm{St}_{\mathrm{f}} / \mathrm{St}_{\mathrm{o}}}$ variation with $\mathrm{x} / \mathrm{d}$ is evident for each value of $\mathrm{m}$ for $\mathrm{x} / \mathrm{d}>30$. Third, for each $\mathrm{x} / \mathrm{d}, \overline{\mathrm{St}_{\mathrm{f}} / \mathrm{St}_{\mathrm{o}}}$ values generally increase with $\mathrm{m}$. The only exception to this last observation occurs at $\mathrm{m}=4.0$ when $\mathrm{x} / \mathrm{d}<40 . \overline{\mathrm{St}_{\mathrm{f}} / \mathrm{St}_{\mathrm{o}}}$ values at these conditions are lower than at other blowing ratios because the high film momentum causes it to be located far from the test surface very quickly after it exits the holes.

As blowing ratio ranges from 1.5 to $4.0, \overline{\mathrm{St}_{\mathrm{f}} / \mathrm{St}_{\mathrm{o}}}$ data in Figure 4 range between 1.05 and 1.3. $\overline{\mathrm{St}_{\mathrm{f}} / \mathrm{St}_{\mathrm{o}}}$ values for $\mathrm{m}$ $=3.0$ are roughly the same as $\overline{\mathrm{St}_{\mathrm{f}} / \mathrm{St}_{\mathrm{o}}}$ values for $\mathrm{m}=4.0$ at $\mathrm{x} / \mathrm{d}>40$, and are considerably higher than magnitudes measured at lower $\mathrm{m}$. Such behavior results as the film reattaches to boundary layer regions near the test surface with increased magnitudes of turbulence and mixing.

\section{Surveys of Streamwise Mean Velocity}

Surveys of streamwise mean velocity measured downstream of the single row of film cooling holes at $\mathrm{x} / \mathrm{d}=9.9$ are presented in Figure 5 for blowing ratios of 1.5, 2.0, 3.0, and 4.0. In each case, contour levels of local streamwise mean velocity normalized by the freestream mean velocity, $\mathrm{U} / \mathrm{U}_{x}$, are given. Arrows along the bottom abscissa indicate spanwise locations of the film holes.

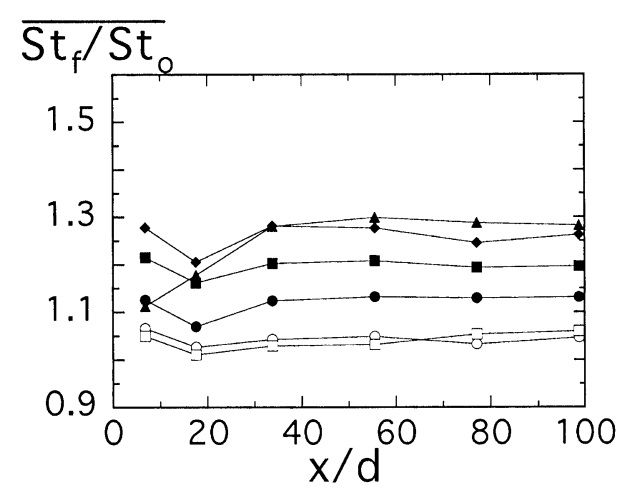

FIGURE 4 Spanwise-averaged magnitudes of iso-energetic Stanton number ratio as dependent upon normalized streamwise distance downstream of one row of compound angle configuration 3 film cooling holes. Symbol labels are given in Figure 3. 
$\mathrm{y} / \mathrm{d}$
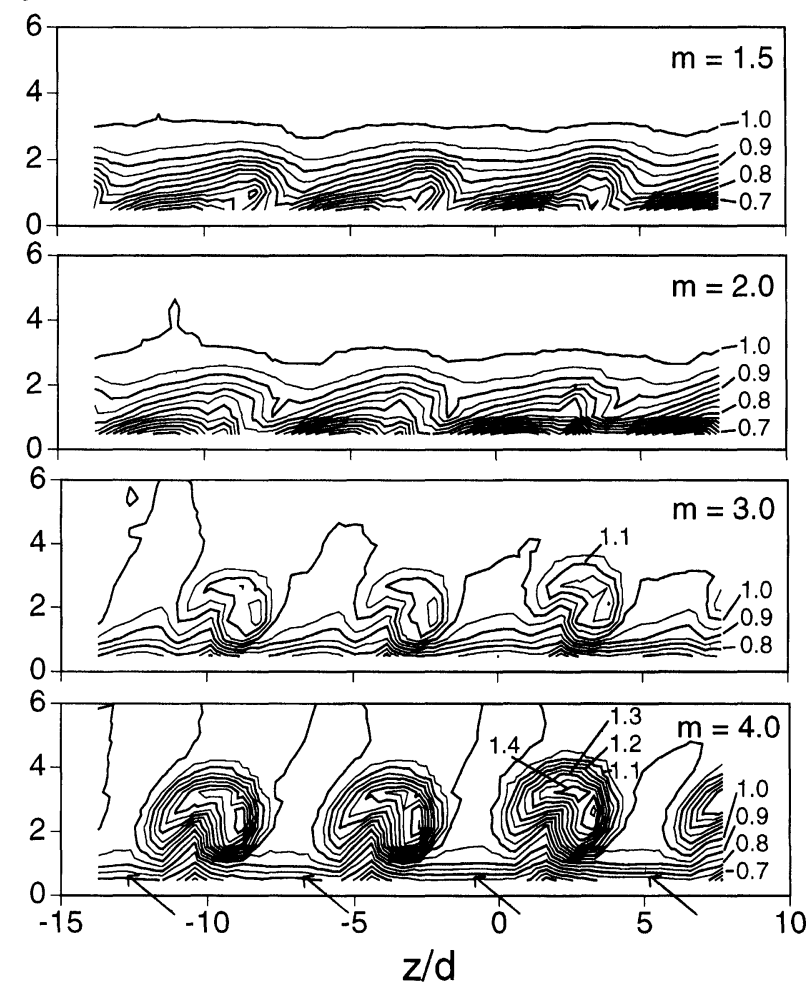

FIGURE 5 Streamwise mean velocity distributions measured downstream of one row of compound angle configuration 3 holes at $\mathrm{x} / \mathrm{d}=$ 9.9 for $\mathrm{m}=1.5,2.0,3.0$, and 4.0.

Figure 5 shows that velocity deficits produced by the injectant from different holes are quite similar across the span of the measurement plane for each value of $\mathrm{m}$. At $\mathrm{m}$ $=1.5$, and $\mathrm{m}=2.0$, each velocity deficit is skewed and flattened with the largest gradients in the direction that film is ejected from the surface at $\mathrm{y} / \mathrm{d}$ ranging from 0.5 to 2.0. Because of the negative spanwise components of velocity at the exits of the film holes, deficits at these $\mathrm{m}$ are also displaced about $-2.5 \mathrm{~d}$ to $-3.5 \mathrm{~d}$ by the time they reach $\mathrm{x} / \mathrm{d}=9.9$.

Figure 5 also shows that the velocity perturbations produced by the film at $\mathrm{m}=3.0$ and $\mathrm{m}=4.0$ are significantly different from the deficits produced by the film at lower $\mathrm{m}$. With $\mathrm{m}=3.0$ and $\mathrm{m}=4.0$, the local velocity perturbation downstream of each film hole is "kidney" shaped and angled from the streamwise/normal plane. In each these regions, magnitudes of $\mathrm{U} / \mathrm{U}{ }_{x}$ are higher than 1.0, being greater than 1.15 at $\mathrm{m}=3.0$ and greater than 1.4 at $\mathrm{m}=4.0$. Very large spanwise and normal gradients are then evident at $\mathrm{y} / \mathrm{d}$ from 0.5 to 3.0 below these local $\mathrm{U} / \mathrm{U}_{x}$ maxima.
As the blowing ratio increases from 1.5 to 4.0 , the velocity regions most strongly affected by the film are located farther and farther from the test surface. At $\mathrm{m}=$ 4.0 , local velocity maxima are located near $\mathrm{y} / \mathrm{d}=3.0$. In addition, each velocity perturbation is displaced by increased distances from its originating injection hole as the blowing ratio $\mathrm{m}$ increases. At $\mathrm{m}=3.0$, perturbations are located $-2.0 \mathrm{~d}$ to $-4.0 \mathrm{~d}$ away from their originating holes, and at $\mathrm{m}=4.0$, perturbations are located $-2.0 \mathrm{~d}$ to $-6.0 \mathrm{~d}$ away from their originating holes.

\section{Surveys of Injection Distributions}

Injection distribution surveys measured downstream of the compound angle injection holes are presented in Figure 6 at $\mathrm{x} / \mathrm{d}=9.9$ for blowing ratios of 1.5, 2.0, 3.0,

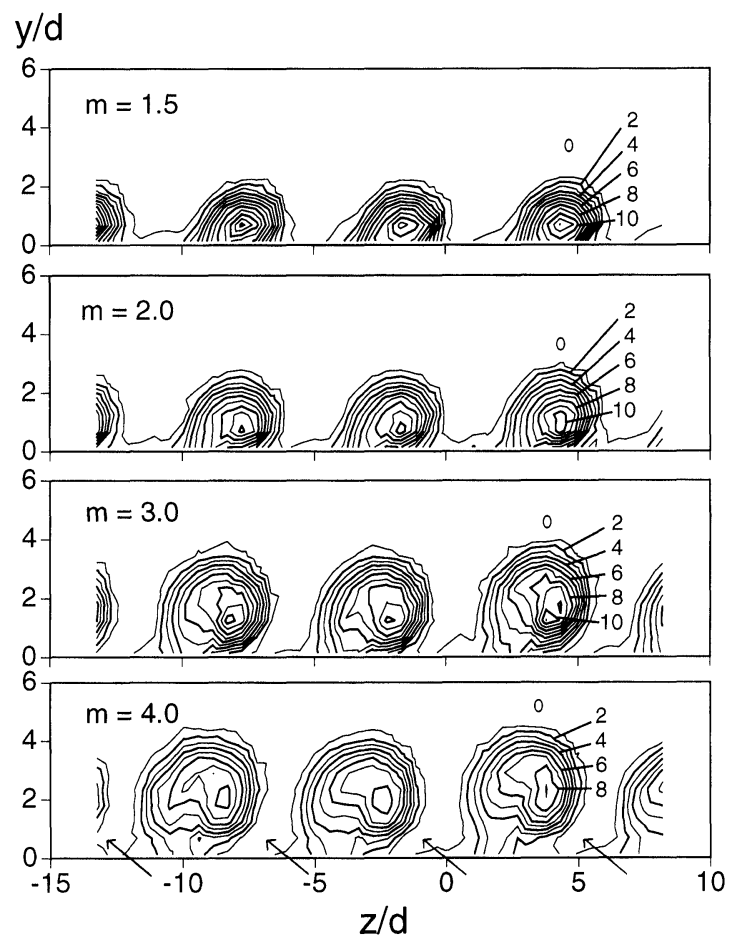

FIGURE 6 Mean temperature fields showing distributions of film injectant measured downstream of one row of compound angle configuration 3 holes at $\mathrm{x} / \mathrm{d}=9.9$ for $\mathrm{m}=1.5,2.0,3.0$, and 4.0.

$\left(T_{r}-T_{r},{ }_{x}\right)\left({ }^{\circ} \mathrm{C}\right)$ CONTOUR LEVELS

$\begin{array}{llrl}0 & <0.5 & 6 & 5.0-6.0 \\ 1 & 0.5-1.0 & 7 & 6.0-7.0 \\ 2 & 1.0-2.0 & 8 & 7.0-8.0 \\ 3 & 2.0-3.0 & 9 & 8.0-9.0 \\ 4 & 3.0-4.0 & 10 & >9.0 \\ 5 & 4.0-5.0 & & \end{array}$


and 4.0. These distributions are obtained using procedures described by Ligrani et al. (1989) in which the injectant is heated without providing any heat to the test plate. With this approach, the injectant is the only source of thermal energy relative to the freestream flow. Distributions of $\left(\mathrm{T}_{\mathrm{r}}-\mathrm{T}_{\mathrm{r}}, x_{x}\right)$, such as the ones in Figure 6, thus show how injectant accumulates and is rearranged in the boundary layer by advection including any secondary flows which may be present. Thus, the temperature field is employed here to show injectant distributions in the spanwise/normal plane at $\mathrm{x} / \mathrm{d}=9.9$.

For each $\mathrm{m}$, injectant distributions in Figure 6 are spanwise periodic such that individual distributions are similar to each other, as expected. For each $\mathrm{m}$ value shown, injectant accumulations at $\mathrm{x} / \mathrm{d}=9.9$ are most significant just to the left of the spanwise center lines of the injection holes (i.e. at smaller $\mathrm{z}$ ). The accumulations for the smaller $m$ are, of course, advected away from the injection holes a smaller distance in the spanwise direction. This spanwise shift with streamwise convection is consistent with the results in figure 5, since injectant accumulations for all four $\mathrm{m}$ show close correspondence to streamwise velocity deficits or streamwise mean velocity local maxima. One injectant accumulation is present for each velocity local maxima or local minima such that accumulations generally lie just to the right (i.e. at larger z) of streamwise velocity deficits.

As the blowing ratio increases from 1.5 to 4.0 , Figure 6 also shows injectant concentrations for $\mathrm{x} / \mathrm{d}=9.9$ which are located farther and farther from the test plate (i.e. farther from $y / d=0$ ). Such lift-off behavior is consistent with results in Figures 3 and 5, and with results presented by Ligrani et al. (1992, 1994b). In those studies as well as in the present one, both spanwise averaged $\bar{\eta}$ and local $\eta$ minima decrease in magnitude as the blowing ratio increases because of decreased local protection, which results as increasing amounts of injectant are lifted off the test surface.

In Figure 6, skewed and lop-sided injectant concentrations are evident in the spanwise/normal plane at $\mathrm{x} / \mathrm{d}$ $=9.9$ for all four $\mathrm{m}$ values. Between these concentrations, well defined deficits of injectant are evident which closely correspond with $\eta$ minima (Wigle, 1991). With streamwise advection to $\mathrm{x} / \mathrm{d}$ of 44.3 and 86.3 , injectant accumulations become more diffuse and dissipated (Wigle, 1991; Ligrani et al., 1994b).

\section{Overall Film Cooling Performance}

The overall film cooling performance parameter $\mathrm{q}^{\prime \prime} / \mathrm{q}_{\mathrm{o}}{ }^{\prime \prime}$ is presented in figures 7 and 8 as dependent upon normalized streamwise distance, $x / d$. Here, $q^{\prime \prime}$ is the surface heat

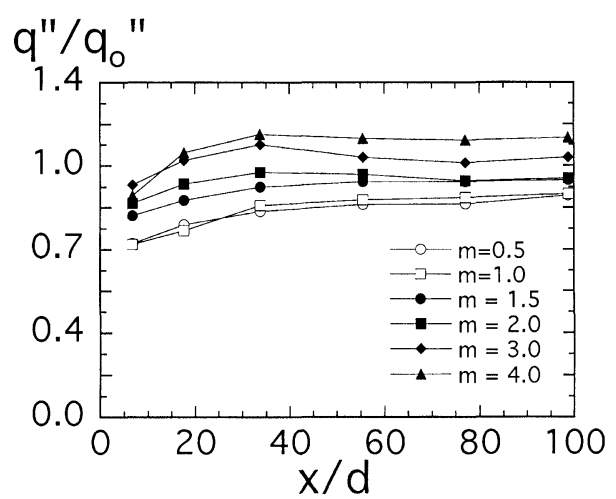

FIGURE 7 Overall film cooling performance parameter as dependent upon normalized streamwise distance downstream of one row of compound angle configuration 3 film cooling holes.

flux with film cooling and $\mathrm{q}_{\mathrm{o}}{ }^{\prime \prime}$ is the baseline surface heat flux with no film cooling. The ratio is a spanwiseaveraged quantity determined from variations of $\bar{\eta}$ and $\overline{\mathrm{St}_{\mathrm{f}} / \mathrm{St}_{\mathrm{o}}}$ at $\theta=1.75$. It is especially informative here as it illustrates the degradation of protection of film cooling from compound angle holes as the blowing ratio increases. Lower $\mathrm{q}^{\prime \prime} / \mathrm{q}_{\mathrm{o}}$ " values indicate better protection, and $\mathrm{q}^{\prime \prime} / \mathrm{q}_{\mathrm{o}}$ " values greater than 1 indicate film cooling heat flux magnitudes which are augmented above baseline values with no film cooling.

The results from compound angle configuration 3 in figure 7 show that the protection decreases at each $\mathrm{x} / \mathrm{d}$ as the blowing ratio increases. The only exceptions are evident at $\mathrm{m}=0.5$ and $\mathrm{m}=1.0$ which give about the same $\mathrm{q}^{\prime \prime} / \mathrm{q}_{\mathrm{o}}$ " at all $\mathrm{x} / \mathrm{d}$, and at $\mathrm{m}=4.0$ which gives $\mathrm{q}^{\prime \prime} / \mathrm{q}_{\mathrm{o}}$ " which are lower than the $m=3.0$ value at $x / d=6.8$.

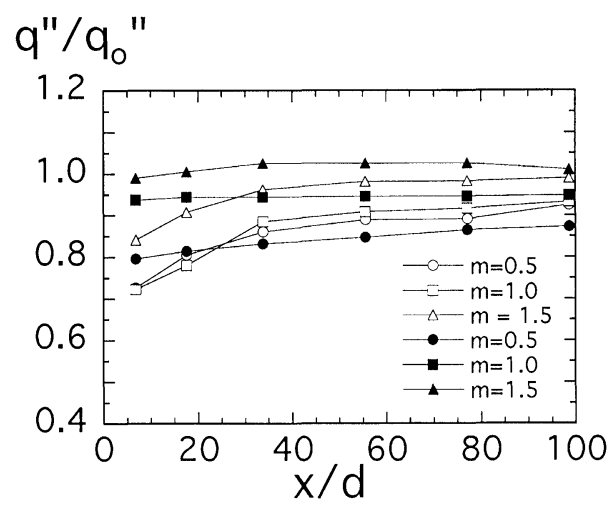

FIGURE 8 Overall film cooling performance parameter downstream of one row of compound angle configuration 3 film cooling holes (open symbols) and one row of simple angle configuration 2 film cooling holes (closed symbols). 
In figure 8 , results from single angle configuration 2 from Ligrani et al. (1994b) (closed symbols) are compared to the compound angle results from the present study (open symbols). The simple angle configuration employs holes oriented in streamwise/normal planes and inclined $35^{\circ}$ from the test surface with the same spanwise hole spacing of $6 \mathrm{~d}$ as the configuration 3 arrangement. Figure 8 shows that compound angle film cooling gives better overall performance at $\mathrm{m}=1.0$ and $\mathrm{m}=1.5$ for all $\mathrm{x} / \mathrm{d}$, and at $\mathrm{m}=0.5$ when $\mathrm{x} / \mathrm{d}<25$.

\section{PRACTICAL IMPORTANCE}

The results presented in this paper are practically important as they are applied to the design of cooling schemes for turbine surfaces located in the first stages of gas turbine engines.

\section{SUMMARY AND CONCLUSIONS}

Experimental results are presented which describe the development and structure of flow downstream of a single row of film-cooling holes with compound angle orientations at blowing ratios of 1.5, 2.0, 3.0, and 4.0. With this configuration, which is denoted number 3 , holes are spaced $6 \mathrm{~d}$ apart in the spanwise direction with inclination angles of 24 degrees, and orientation angles of 50.5 degrees. Results are presented for an injectant to freestream density ratio near 1.0 , and $\mathrm{x} / \mathrm{d}$ ranging from 6.8 to 98.7 .

Spanwise-averaged values of the adiabatic film cooling effectiveness measured downstream of configuration 3 are highest with a blowing ratios of 1.5 and 2.0 , and decrease with blowing ratio at individual $\mathrm{x} / \mathrm{d}$ because of injection jet lift-off effects for $\mathrm{x} / \mathrm{d}<40$. The extents of lift-off at $\mathrm{m}=1.5, \mathrm{~m}=2.0, \mathrm{~m}=3.0$, and $\mathrm{m}=4.0$ are confirmed by injection distribution surveys presented for $\mathrm{x} / \mathrm{d}=9.9$. Lift-off results in spanwise periodic concentrations of injectant and spanwise variations of local protection at $\mathrm{x} / \mathrm{d}=6.8$. As the boundary layers advect farther downstream to $\mathrm{x} / \mathrm{d}>40, \bar{\eta}$ values decrease with $\mathrm{m}$ at each $\mathrm{x} / \mathrm{d}$ with the exception of measurements made at $\mathrm{m}=1.5$. According to Wigle (1991), the different trend observed for $m=1.5$ is due to differences in the ways in which the injectant at different blowing ratios lifts-off and spreads relative to the test surface.

As blowing ratio ranges from 1.5 to $4.0, \overline{\mathrm{St}_{\mathrm{f}} / \mathrm{St}_{\mathrm{o}}}$ data range between 1.05 and 1.3. $\overline{\mathrm{St}_{\mathrm{f}} / \mathrm{St}_{\mathrm{o}}}$ values for $\mathrm{m}=3.0$ are roughly the same as $\overline{\mathrm{St}_{\mathrm{f}} / \mathrm{St}_{\mathrm{o}}}$ values for $\mathrm{m}=4.0$ at $\mathrm{x} / \mathrm{d}$ $>40$, and are considerably higher than magnitudes measured at lower $\mathrm{m}$. Such behavior results as the film reattaches to boundary layer regions near the test surface with increased magnitudes of turbulence and mixing. In addition, (i) $\overline{\mathrm{St}_{\mathrm{f}} / \mathrm{St}_{\mathrm{o}}}$ values for all blowing ratios for all $\mathrm{x} / \mathrm{d}$ are greater than 1.0 , (ii) little $\overline{\mathrm{St}_{\mathrm{f}} / \mathrm{St}_{\mathrm{o}}}$ variation with $\mathrm{x} / \mathrm{d}$ is evident for each value of $\mathrm{m}$ for $\mathrm{x} / \mathrm{d}>30$, and (iii) for each $\mathrm{x} / \mathrm{d}, \overline{\mathrm{St}_{\mathrm{f}} / \mathrm{St}_{\mathrm{o}}}$ values generally increase with $\mathrm{m}$.

Overall spanwise-averaged compound angle film cooling performance generally decreases as $m$ increases from 1.0 to 4.0 for the range of $\mathrm{x} / \mathrm{d}$ investigated. In addition, compound angle film cooling gives better overall performance compared to simple angle holes (with the same spanwise hole spacing) at $\mathrm{m}=1.0$ and $\mathrm{m}=1.5$ for all $\mathrm{x} / \mathrm{d}$ examined and at $\mathrm{m}=0.5$ when $\mathrm{x} / \mathrm{d}<25$.

\section{Nomenclature}

d

jection hole diamete

$\mathrm{m} \quad$ blowing ratio, $\rho_{\mathrm{c}} \mathrm{U}_{\mathrm{c}} / \rho_{x} \mathrm{U}_{x}$

$q^{\prime \prime} \quad$ surface heat flux with film cooling

$\mathrm{q}_{\mathrm{o}}$ " baseline surface heat flux, no film cooling

St Stanton number with film injection

$\mathrm{St}_{\mathrm{o}} \quad$ baseline Stanton number, no film injection

$\underline{S t}_{f} \quad$ iso-energetic Stanton number with film injection

$\mathrm{St}_{\mathrm{f}} \quad$ spanwise-averaged iso-energetic Stanton number with film injection

temperature

velocity

$\mathrm{X}, \mathrm{X} \quad$ streamwise distance

$\mathrm{y}$ distance normal to the surface

$\mathrm{z} \quad$ spanwise distance from test surface centerline

$\eta \quad$ adiabatic film cooling effectiveness, $\left(\mathrm{T}_{\mathrm{aw}}-\mathrm{T}_{\mathrm{r}},{ }_{x}\right) /$ $\left(\mathrm{T}_{\mathrm{r} . \mathrm{c}}-\mathrm{T}_{\mathrm{r}},{ }_{\infty}\right)$

$\bar{\eta} \quad$ spanwise-averaged adiabatic film cooling effectiveness

$\theta$ non-dimensional injection temperature, $\left(\mathrm{T}_{\mathrm{r} . \mathrm{c}}-\mathrm{T}_{\mathrm{r}}\right.$, $\left.{ }_{x}\right) /\left(\mathrm{T}_{\mathrm{w}}-\mathrm{T}_{\mathrm{r}},{ }_{\infty}\right)$

$\Omega \quad$ injection hole angle with respect to the test surface as projected into the streamwise/normal plane

$\beta \quad$ injection hole angle with respect to the test surface as projected into the spanwise/normal plane

$\rho \quad$ density

subscripts

aw adiabatic wall

c injectant at exits of injection holes

o stagnation condition or baseline data

$r \quad$ recovery condition

w wall

$x \quad$ freestream

superscripts

spanwise average 


\section{References}

Ekkad S. V., Zapata D., and Han J.-C., 1995a, Heat Transfer Coefficients Over a Flat Surface With Air and $\mathrm{CO}_{2}$ Injection Through Compound Angle Holes Using a Transient Liquid Crystal Image Method, accepted for publication in the ASME Transactions Journal of Turbomachinery:

Ekkad S. V., Zapata D., and Han J.-C., 1995b, Film Effectiveness Over a Flat Surface With Air and $\mathrm{CO}_{2}$ Injection Through Compound Angle Holes Using a Transient Liquid Crystal Image Method, accepted for publication in the ASME Transactions Journal of Turbomachinerv.

Goldstein R. J., Eckert E. R. G., Eriksen V. L., and Ramsey J. W., 1970, Film Cooling Following Injection Through Inclined Circular Tubes, Israel Journal of Technology, Vol: 8, pp. 145-154.

Honami S., and Fukagawa M., 1987, A Study on Film Cooling Behavior of a Cooling Jet Over a Concave Surface, Paper No 87-Tokyo IGTC-72, Proceedings of the 1987 Tokyo International Gas Turbine Congress, Vol. 3, pp. 209-216.

Honami S., Shizawa T., and Uchiyama A., 1994, Behavior of the Laterally Injected Jet in Film Cooling: Measurements of Surface Temperature and Velocity/Temperature Field Within the Jet, $A S M E$ Transactions-Journal of Turbomachinery, Vol. 116, No. 1, pp. 106-112.

Kim H. K., Moffat R. J., and Kays W. M., 1978, Heat Transfer to a Full-Coverage, Film-Cooled Surface With Compound-Angle $\left(30^{\circ}\right.$ and $45^{\circ}$ ) Hole Injection, Report HMT-28, Thermosciences Division, Department of Mechanical Engineering, Stanford University, Stanford, $\mathrm{Ca}$.

Ligrani P. M., Ciriello S., and Bishop D. T., 1992, Heat Transfer, Adiabatic Effectiveness, and Injectant Distributions Downstream of a Single Row and Two Staggered Rows of Compound Angle FilmCooling Holes, ASME Transactions-Journal of Turbomachinery, Vol. 114, No. 4, pp. 687-700.

Ligrani P. M., Ortiz A., Joseph S. L., and Evans D. L., 1989, Effects of Embedded Vortices on Film-Cooled Turbulent Boundary Layers, ASME Transactions-Journdl of Turbomdchinery, Vol. 111, No. 1, pp. 71-77.

Ligrani P. M., and Ramsey A. E., 1996a, Film Cooling From Spanwise Oriented Holes in Two Staggered Rows, to appear, ASME Transactions-Journal of Turbomachinery:
Ligrani P. M., and Ramsey A. E., 1996b, Film Cooling From a Single Row of Holes Oriented in Spanwise/Normal Planes, submitted for publication in the ASME Transactions-Journal of Turbomachinery.

Ligrani P. M., Wigle J. M., Ciriello S., and Jackson S. M., 1994a, Film Cooling From Holes With Compound Angle Orientations, Part 1: Results Downstream of Two Staggered Rows of Holes With 3d Spanwise Spacing, ASME Transactions-Journal of Heat Transfer, Vol. 116, No. 2, pp. 341-352.

Ligrani P. M., Wigle J. M., and Jackson S. M., 1994b, Film Cooling From Holes With Compound Angle Orientations, Part 2: Results Downstream of a Single Row of Holes With 6d Spanwise Spacing, ASME Transactions-Journal of Heat Transfer, Vol. 116, No. 2, pp. 353-362.

Mayle R. E., and Camarata F. J., 1975, Multihole Cooling Film Effectiveness and Heat Transfer, ASME Transactions-Journal of Heat Transfer, Vol. 97, pp. 534-538.

Pederesen D. R., Eckert E. R. G., and Goldstein R. J., 1977, Film Cooling With Large Density Differences Between the Mainstream and the Secondary Fluid Measured by the Heat-Mass Transfer Analogy, ASME Transactions-Journal of Heat Transfer, Vol. 99, pp. 620-627.

Sathyamurthy P., and Patankar S. V., 1990, Prediction of Film Cooling With Lateral Injection, ASME-HTD Vol. 138, Heat Transfer in Turbulent Flows, pp. 61-70.

Schmidt D. L., Sen B., and Bogard D. G., 1994, Film Cooling With Compound Angle Holes: Adiabatic Effectiveness, Paper No. 94-GT312, ASME International Gas Turbine and Aeroengine Congress and Exposition, The Hague, Netherlands, June 13-16.

Sen B., Schmidt D. L., and Bogard D. G., 1994, Film Cooling With Compound Angle Holes: Heat Transfer, Paper No. 94-GT-311, ASME International Gas Turbine and Aeroengine Congress and Exposition, The Hague, Netherlands, June 13-16.

Wigle J. M., 1991, Heat Transfer, Adiabatic Effectiveness and Injectant Distributions Downstream of Single and Double Rows of FilmCooling Holes with Compound Angles, M. S. Thesis, Department of Mechanical Engineering, Naval Postgraduate School, Monterey. 

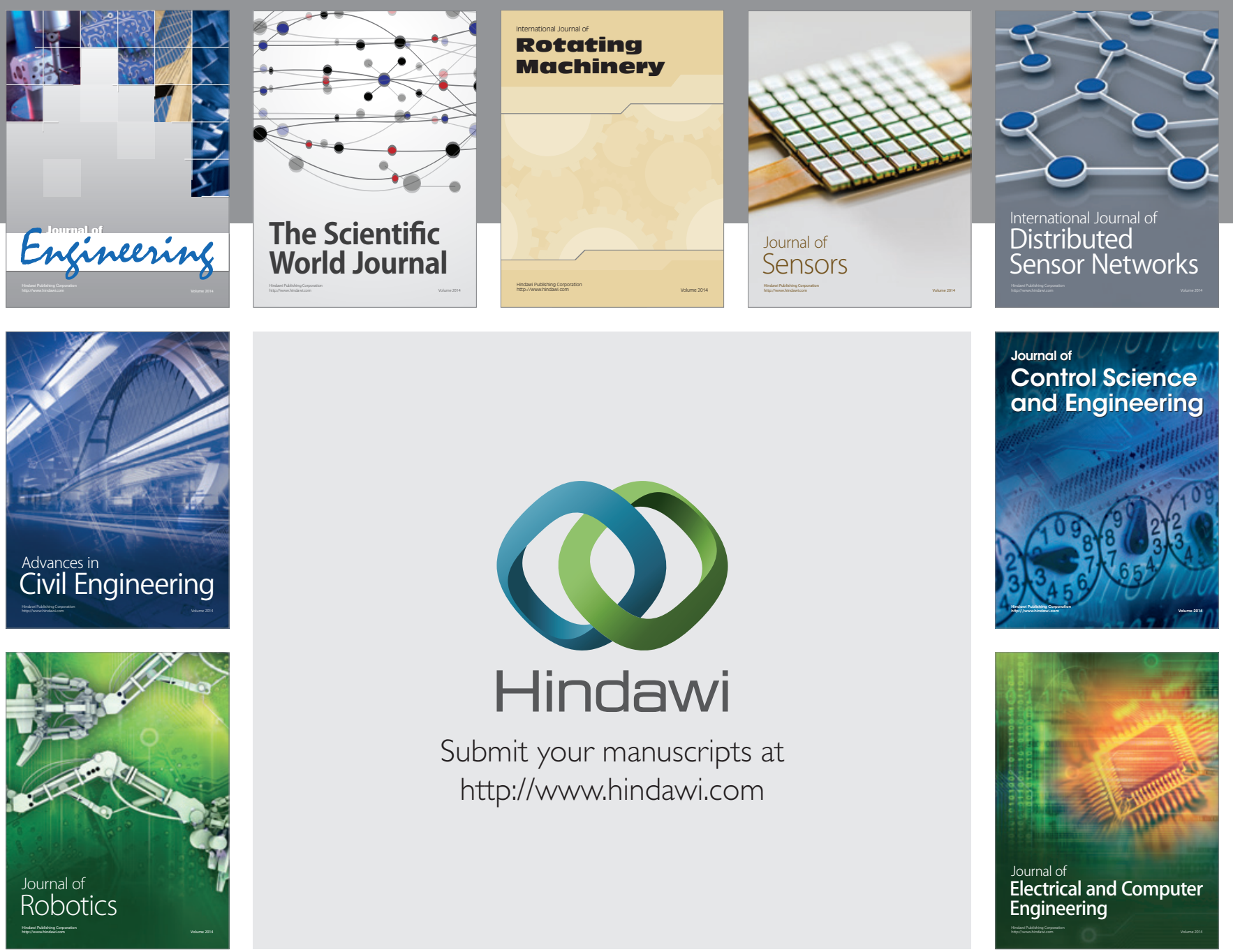

Submit your manuscripts at

http://www.hindawi.com
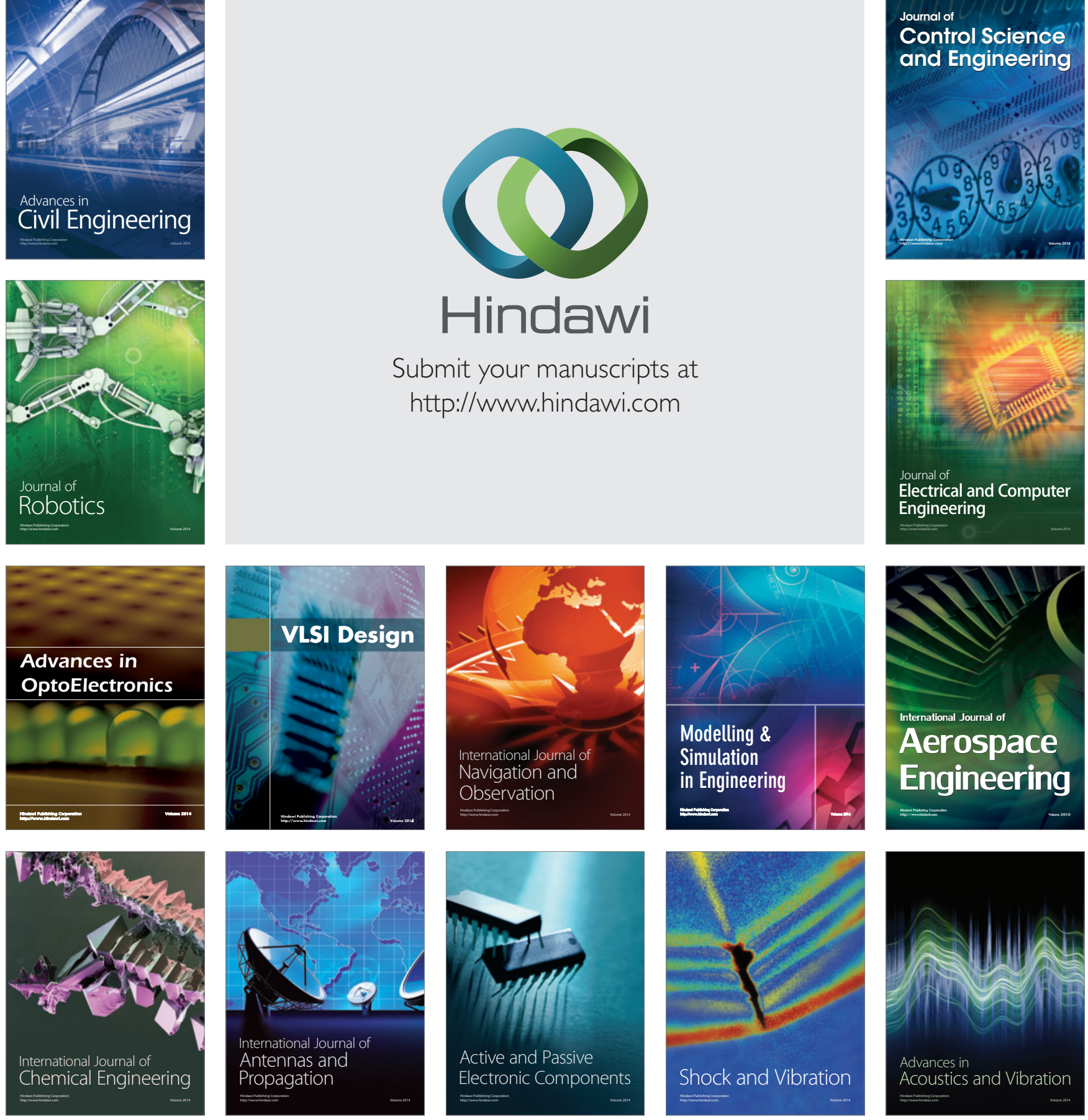